\title{
RUNNING VELOCITY DYNAMICS IN 100 M SPRINT: COMPARATIVE ANALYSIS OF THE WORLD TOP AND ESTONIAN TOP MALE SPRINTERS
}

\author{
M. Misjuk ${ }^{1}$, M. Viru ${ }^{2}$ \\ ${ }^{1}$ Institute of Health Science and Sports, \\ University of Tallinn, Tallinn, Estonia \\ ${ }^{2}$ Institute of Sports Pedagogy and Coaching, University of Tartu, Tartu,
} Estonia

\begin{abstract}
Estonian sprint runners have not achieved great success in international title competitions. This study was conducted to analyze their performance in $100 \mathrm{~m}$ race. The aim of this study was to perform a comparative analysis of $100 \mathrm{~m}$ sprint horizontal velocity dynamics in Estonian top level and world top-level male sprinters. We analyzed: 1) athletes' relative running velocity during different phases of the distance; 2) the loss of Estonian sprinters to the world best sprinters during different phases of the distance.

The study compared Estonian Athletics Championships (2006) men's $100 \mathrm{~m}$ sprint final results with Berlin World Athletics Championships (2009) men's 100m final results. In both competitions, interval times were measured for the following sections of the race: 0 $30 \mathrm{~m}, 30-60 \mathrm{~m}, 60-80 \mathrm{~m}$ and $80-100 \mathrm{~m}$. We found out that Estonian sprinters' acceleration ability is relatively better than the other physical abilities necessary for achieving good results in $100 \mathrm{~m}$. Estonian sprinters loose most to the world best sprinters during the last part of the distance, $80-100 \mathrm{~m}$. However, the difference in running velocity of Estonian sprinters compared to the world best runners is approximately the same in all three last sections of the distance (30$60 \mathrm{~m}, 60-80$ and $80-100 \mathrm{~m})$.
\end{abstract}

Key words: sprint running, $100 \mathrm{~m}$, running velocity, Estonian sprinters 


\section{INTRODUCTION}

The $100 \mathrm{~m}$ can rightly be considered the most remarkable event of athletics at major championships. The sheer speed of the $100 \mathrm{~m}$ allows the winner to claim that he is the fastest runner in the country or in the world. The world best sprinters run $100 \mathrm{~m}$ faster than 10 seconds, which makes the average velocity over the distance more than $10 \mathrm{~m}$ per seconds. The world-class athletes make in average 45 steps in a world championship finals $[4,14]$. However, during this short time and small number of steps the sprinter experiences four different phases of speed. First, the reaction speed phase in the start; second, the acceleration phase; third, the maximal speed phase; fourth, the speed maintenance phase $[8,13,14,15]$. Reaction time is a contributor to the overall sprint time, however since it has not been found to be related to sprint performance [9], it was not focused upon in this study.

Different speed abilities have different importance in different sprint distances $(100-400 \mathrm{~m})$. In $100 \mathrm{~m}$ sprint running at maximal velocity is often taken as the most important part of the race $[1,2,5]$. According to Ralph Mann the most obvious general performance descriptor in the sprint is horizontal velocity. Ignoring the importance of the start, the athlete that can produce the greatest amount of horizontal velocity will be the most successful [9].

The aim of this study was to perform a comparative analysis of $100 \mathrm{~m}$ sprint horizontal velocity dynamics in Estonian top level and world top level male sprinters. We analyzed: 1) athletes' relative running velocity during different phases of the distance; 2) the loss of Estonian sprinters to the world best sprinters during different phases of the distance.

\section{MATERIALS AND METHODS}

The subjects of the study were 7 Estonian top male sprinters who took part in the final race of $100 \mathrm{~m}$ in Estonian national championships in Tallinn (21.07.2006). The measurements of running velocity during different phases of $100 \mathrm{~m}$ distance were done in the following sections: $0-30 \mathrm{~m}, 30-60 \mathrm{~m}, 60-80 \mathrm{~m}$ and $80-100 \mathrm{~m}$. The timing system "Ivar" (accuracy 1/1000 s) designed and built by Ivar Krause was used to measure these split times. The final time of the race was taken from the official competition protocol of results. The timing system of the championships was produced by "Omega" (Switzerland). 


\section{Statistical analysis}

The relative running velocities (\%) of Estonian and world best sprinters in different sections of $100 \mathrm{~m}$ race $(0-30 \mathrm{~m}, 30-60 \mathrm{~m}, 60-80 \mathrm{~m}$ and $80-100 \mathrm{~m}$ ) were calculated taking the average velocity of the whole distance as $100 \%$. Another calculation was made to find the ratio of Estonian runners' average velocities to world top sprinters average velocities in different sections of the $100 \mathrm{~m}$ distance. $100 \%$ corresponded to the average velocities of different sections of the race in 2009 Berlin World Championship final.

The comparative data about the performance of the world best sprinters was taken from the analysis of 2009 Berlin World Athletics Championships $100 \mathrm{~m}$ final race [6].

The both finals were run in similar good weather conditions with a tail wind: $+0.6 \mathrm{~m} / \mathrm{s}$ in Estonian Championships and $+0.9 \mathrm{~m} / \mathrm{s}$ in World Championships. Though the difference of $0.3 \mathrm{~m} / \mathrm{s}$ of wind speed can slightly influence the results in $100 \mathrm{~m}$ sprint according to J. Mureika calculations [11] we did not considered this small difference relevant enough to make any corrections in our calculations.

\section{RESULTS}

The Estonian sprinters showed results in $100 \mathrm{~m}$ final race from $10.51 \mathrm{~s}$ up to $11.21 \mathrm{~s}$. These results can be considered quite average during this decade. Table 1 presents the split times and the final results of 2006 Estonian Athletics Championships men's 100m final.

Table 1. The split times of men's 100m final in 2006 Estonian Athletics Championships

\begin{tabular}{|l|c|c|c|c|}
\hline \multirow{2}{*}{ Athlete } & \multicolumn{4}{|c|}{ Time } \\
\cline { 2 - 5 } & $\mathbf{3 0 m}$ & $\mathbf{6 0 m}$ & $\mathbf{8 0 m}$ & $\mathbf{1 0 0 m}$ \\
\hline 1. & 4.02 & 6.77 & 8.61 & 10.51 \\
\hline 2. & 4.05 & 7.00 & 8.89 & 10.84 \\
\hline 3. & 4.03 & 6.91 & 8.85 & 10.93 \\
\hline 4. & 4.06 & 7.07 & 9.00 & 11.00 \\
\hline 5. & 4.08 & 7.17 & 9.10 & 11.12 \\
\hline 6. & 4.06 & 7.12 & 9.11 & 11.15 \\
\hline 7. & 4.09 & 7.20 & 9.17 & 11.21 \\
\hline Mean \pm SD & $4.06 \pm 0.02$ & $7.03 \pm 0.14$ & $8.96 \pm 0.18$ & $10.97 \pm 0.22$ \\
\hline
\end{tabular}


Figure 1 presents the Estonian and the world best male $100 \mathrm{~m}$ sprinters relative velocities in different sections of the distance. The base for the comparison was the average running velocity over the whole $100 \mathrm{~m}$ distance. The value of the distance average velocity was taken to be equal to $100 \%$. The values over $100 \%$ showed higher velocity and values lower than $100 \%$ lower velocity than average in different phases of the distance.

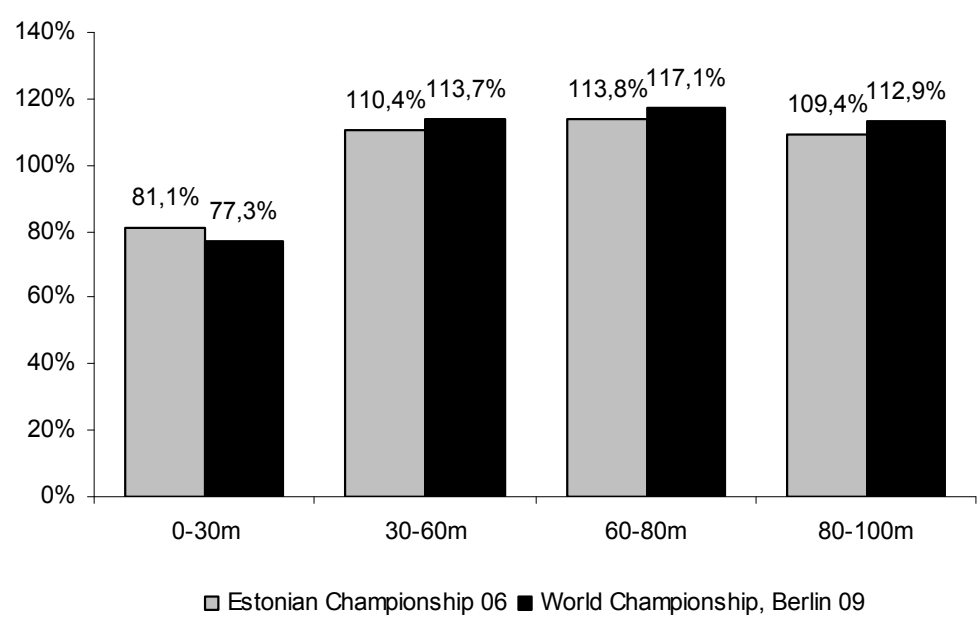

Figure 1. The relative running velocities of Estonian and world best male sprinters in different sections of $100 \mathrm{~m}$ race: $0-30 \mathrm{~m}, 30-60 \mathrm{~m}, 60-80 \mathrm{~m}$ and $80-100 \mathrm{~m} .100 \%$ corresponds to the average velocity of the whole distance.

Figure 2 shows how much Estonian sprinters are slower than to the world best sprinters in different phases of $100 \mathrm{~m}$ sprint. Again, similar to previous analysis the followed distance sections were $0-30 \mathrm{~m}, 30$ $60 \mathrm{~m}, 60-80 \mathrm{~m}$ and $80-100 \mathrm{~m}$. 


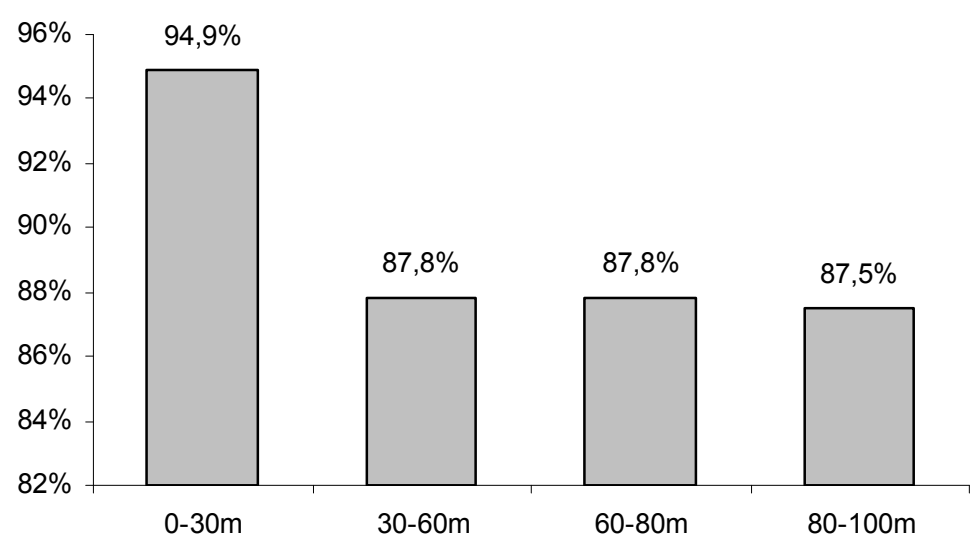

Figure 2. The ratio of Estonian top sprinters' average velocities to the world top sprinters' average velocities in different sections of $100 \mathrm{~m}$ race. $100 \%$ corresponds to the average velocities of different sections of the $100 \mathrm{~m}$ race in 2009 Berlin World Championships final.

\section{DISCUSSION}

This study analyzed horizontal running velocity dynamics of Estonian and world best $100 \mathrm{~m}$ male sprinters according to the data obtained from 2006 Estonian Championships (abbreviated as EC) and 2009 World Athletics Championships (abbreviated as WC).

\section{Athletes' relative running velocity during different phases of the distance}

The relative running velocities of Estonian and the world best athletes is presented in Figure 1. The baseline for the comparison is the average velocity over the $100 \mathrm{~m}$ distance. The figures show that only in the first section, during acceleration phase, the running velocity is lower than the average velocity of the whole distance. Estonians achieve $81.1 \%$ of their average velocity over the first $30 \mathrm{~m}$ running distance, while the world best sprinters gain $77.3 \%$ of their average velocity in this phase of race. It does not mean that the Estonian runners are better accelerators as the mean time in this section was better in the world top sprinters (3.85s vs. $4.06 \mathrm{~s})$. But this probably 
shows that sprinters of lower maximal running velocity level need less time to achieve their maximal velocity.

The next section of the distance, 30-60m, was run with a significantly higher velocity. The world best sprinters achieve their maximal running velocity usually during this part of the distance $[7,10,12]$. Estonian sprinters were able to raise their running velocity by $29.0 \%$ in this phase of the race, while the world top sprinters added $36.4 \%$ to their running velocity. The explanation of this different capability to add running velocity in this middle section of the distance is probably also related to differences in the levels of maximal running velocity. Estonian sprinters lower maximal velocity enables them to reach their maximal velocity earlier, but does not enable them to raise running velocity as much as the world top sprinters do in the middle section of the race.

Estonian and world top sprinters showed similar running velocity dynamics in the next section of the distance between $60-80 \mathrm{~m}$. The velocity in both groups remained rather constant with a small raise in average by $3.4 \%$.

The running velocity decreased similarly in both groups of sprinters in the last section of the distance, between 80 and $100 \mathrm{~m}$. Estonian sprinters' running velocity decreased by $4.4 \%$ and the velocity of the world top sprinters by $4.1 \%$.

Whilst Estonian sprinters maximal running velocity is considerably lower than world best ones, then to enhance their performance, the key part for Estonian sprinters should be the last parts of the distance. Estonian sprinters might pay more attention to the developing of speed endurance in their training, as there are more opportunities to develop speed endurance than maximal speed. Estonian sprinters should be able to maintain their lower maximal or close to maximal velocity for a longer time. For example in 1987 Rome World Athletics Championships all the male sprinters showed in the $100 \mathrm{~m}$ final that they were able to achieve maximal running velocity over $11 \mathrm{~m} / \mathrm{s}$ (Johnson and Lewis even $11.76 \mathrm{~m} / \mathrm{s}$ ). There were also sprinters in the first rounds of the competition who achieved the same maximal velocity $(11 \mathrm{~m} / \mathrm{s})$, but did not run faster than $10.50 \mathrm{~m} / \mathrm{s}$. Good level maximal running velocity does not guarantee a good result in $100 \mathrm{~m}$ race, but is a good precondition for it. Hence, attention should be paid to the development speed endurance [10]. 


\section{The loss of Estonian sprinters to the world best runners in running velocity during the different phases of the race}

For this analysis the same data from EC 2006 and WC 2009 men's $100 \mathrm{~m}$ final was used. The results show a clear tendency that Estonian sprinters loose to the world best sprinters less in the first section of the distance $(0-30 \mathrm{~m})$, only $5.1 \%$. The loss to the world top runners is higher and approximately at the same amount (between 12.2\%$12.5 \%)$ for the other sections of the distance $(30-60 \mathrm{~m}, 60-80$ and 80 $100 \mathrm{~m}$ ), (Figure 2). Estonian sprinters have relatively better acceleration ability compared to the rest of the physical abilities necessary to run $100 \mathrm{~m}$ at high level. Estonian sprinters loose to world best sprinters most in the last section of the race $(80-100 \mathrm{~m})$ where the loss rises to 12.5\%. Breizer and Zukov [3] compared world best sprinters with Russian top sprinters and found the same tendency. The Russian sprinters loose most in the last part of the distance between 80 and $100 \mathrm{~m}$ where athlete should be able to maintain the running velocity close to the maximal.

\section{ACKNOWLEDGEMENTS}

The authors would like to thank the head coach of Estonian athletics sprint team Valter Espe and the measurements system designer and technical supporter Ivar Krause.

\section{REFERENCES}

1. Arakawa K. (1990) Analytical Study on Running Velocity Curve. Research Reports of Kanagawa Institute of Technology (Bulletin of Universities and Institutes) 14: 105-109

2. Bowerman W. J., Freeman W. H. (1991) High-Performance Training for Track and Field. Leisure Press, Champaign, Illinois

3. Breizer V., Zukov J. (1984) An Analyses on Sprint Performances. Legkaya Athletika, No 11, reprinted in Modern Athlete and Coach

4. Brüggeman, G. P., Koszewski D., Müller H. (1997) Biomechanical Research Project Athens 1997. Meyer and Meyer Sport, Oxford, 26

5. Cunha L. (2005) The relation between different phases of sprint run and specific strength parameters of lower limbs. ISBS. Beijing 
6. Deutscher Leichtathletic Verband. (2009) Scientific Research Project Biomechanical Analyses of World Championships 2009 Berlin: Final Report, Sprint Men [http://www.iaaf.org/mm/Document/Development/Research/05/64/57 /20100415075418_httppostedfile_1BiomechanicsReportWCBerlin2009_Sprint_Men_19905.pdf]

7. Ferro A., Rivera A., Pagola I., Ferreruela M., Martin À., Rocandio V. (2001) Biomechanical analysis of the 7th World Championships in Athletics Seville 1999. New Study of Athletics. 16: 25-60

8. IAAF. (2009) 100m - For the Expert. http://www.iaaf.org/ community/athletics $/$ trackfield $/$ newsid $=4666 . h t m l$

9. Mann R. (2010) The Mechanics of Sprinting and Hurdling. Las Vegas

10. Moravec P., Ruzicka J., Susanka, P., Dostal, E., Kodejs, M., Nosek, M. (1988) The International Athletic Foundation/IAAF Scientific Project Report: Time analysis of the 100 metres events at the II World Championships in Athletics. New Study of Athletics. 3: 61-96

11. Mureika J. (2001) A realistic quasi-physical model of a $100 \mathrm{~m}$ dash. Can. J. Phys. 79: 697-713

12. Müller H., Hommel H. (1997) Biomechanical research project at VI the world championships in athletics, Athens 1997 - sprints

13. Saunders R. (2004) Five Components of the $100 \mathrm{~m}$ sprint. Modern Athlete and Coach. 42: 1-3

14. Smith M. (2005) High performance sprinting. The Crowood Press Ltd., Ramsbury

15. Sugiyama K., Murata Y., Watanabe H., Takayuki K., Iwase M. (2000) Factor Analysis of Sprint Phases of the Speed Curve of the $100 \mathrm{~m}$ Dash. 18th International Symposium on Biomechanics in Sports Conference, Hong Kong, China, June 25 - 30, proceedings

All internet links were valid in 25.10.2011.

\section{Correspondence to:}

Mikola Misjuk

University of Tallinn

Tondi 55, 11316 Tallinn,

Estonia.

E-mail: mikola.misjuk@gmail.com 